\title{
Pengujian Aplikasi Sistem Monitoring Perkuliahan Menggunakan Standar ISO 25010
}

\author{
Mustari S. Lamada ${ }^{1}$, Alimuddin Sa'ban Miru², Riski Amalia ${ }^{3}$ \\ Pendidikan Teknik Informatika dan Komputer, Universitas Negeri Makassar \\ ${ }^{1}$ mustarilamada@g mail.com \\ 2asmiru63@gmail.com \\ riskiamaliapasehaidamail.com
}

\begin{abstract}
Abstrak - Tujuan dari penelitian ini adalah menjamin tingkat kualitas sistem monitoring perkuliaan agar tidak terjadi error serta menjamin fitur dan fugsionalitasnya dengan melakukan pengujian menggunakan standar ISO 25010. Pengujian dilakukan menggunakan 5 karakteristik pada standar ISO 25010 yaitu functional suitability, usability, reliability, performance efficiency, dan maintainability. Instrumen yang digunakan yaitu kuesioner fungsionalitas, USE Questionnaire, stress testing, load testing, dan maintainability index. Hasil dari penelitian ini adalah sistem monitoring perkuliahan telah memenuhi standar ISO 25010 pada karakteristik functional suitability dengan nilai $100 \%$ (baik), karakteristik usability sebesar 88,5,3\% (sangat layak), karakteristik reliability sebesar $100 \%$ (lolos), karakteristik performance efficiency sebesar 4,2 detik (diterima), dan karakteristik maintainability sebesar 100 (sangat mudah dirawat).
\end{abstract}

Kata Kunci : ISO 25010

\section{PENDAhuluan}

Suatu perangkat lunak perlu dijaga kualitasnya, dimana kualitas bergantung pada kepuasan pelanggan. Perangkat lunak perlu dijaga agar dapat bertahan hidup, dapat bersaing dengan perangkat lunak lain, dan mempertahankan pelanggan Rosa \& Shalahuddin (2011: 209). Senada dengan hal tersebut, Pressman (2012: 485) menyatakan bahwa kualitas perangkat lunak adalah suatu proses perangkat lunak yang efektif diterapkan dan mampu menyediakan produk yang bermanfaat bagi penggunanya. Perangkat lunak yang bermanfaat memiliki tiga poin penting yaitu efektivitas proses perangkat lunak, produk yang mampu mengirimkan konten serta fungsi dan mampu memberi nilai lebih bagi pengguna perangkat lunak. Pentingnya kualitas perangkat lunak dipertegas oleh Crosbi dalam (Sommervillle, 2003: 174) yang berpendapat bahwa perangkat lunak yang dikembangkan harus sesuai dengan kebutuhan dan spesifikasi penggunannya.

Saat ini ada berbagai macam standar pengujian perangkat lunak di antaranya McCall, Boehm, FRUPS, Dromey, Bertoa, ISO 9126, dan ISO 25010 (Miguel, Mauricio, \& Rodriguez, 2014). Dari berbagai standar pengujian tersebut, ISO 9126 dan ISO 25010 merupakan standar internasional dalam pengujian perangkat lunak. Menurut Prof. Azuma dalam konferensi software testing di SOFTEC Malaysia menyebutkan bahwa standar ISO 25010 dikembangkan untuk mengantikan ISO 9126 didasarkan pada berkembangan ICT (Information and Communication Technology) seperti perkembangan mikroprosesor, perkembangan memori, perkembangan tampilan, dan perkembangan media penyimpanan (Veenendaal, 2014). Standar ISO 25010 mempunyai 8 karakteristik yaitu functional suitability, reliability, performance efficiency, usability, security, compatibility, maintainability, dan portability. Menurut Olsina dan rekan-rekan kerjanya dalam (Pressman, 2012) standar kualitas web dinilai dari lima aspek yaitu fungsionalitas, kemudahan penggunaan, keandalan, efisiensi, dan kemudahan pemeliharaan. Jika standar kualitas web Olsina dibandingkan dengan standar ISO 25010 maka pengujian sebuah aplikasi web perlu dilakukan pada karakteristik functional suitability, usability, reliability, performance efficiency, dan maintainability.

Berbeda dari awal kehadirannya, kini internet telah banyak digunakan oleh berbagai pihak khususnya yang bergerak dalam bidang teknologi. Dalam internet salah satu fitur yang sering digunakan yaitu web. Aplikasi web pada mulanya hanya berupa situs yang bersifat statis, tetapi saat ini telah banyak yang bersifat dinamis, interaktif yang digunakan dalam sistem informasi telekomunikasi. Web atau internet merupakan jaringan komputer yang saling terhubung antara jaringan satu dengan jaringan lainnya diseluruh dunia. Kebutuhan akan web sangatlah mutlak diperlukan diera globalisasi ini. Selain memberikan kemudahan di dalam melakukan pekerjaan, juga dapat memberikan hasil yang cepat, tepat dan akurat. Berbagai instansi pun mulai menerapkan sistem berbasis web dalam bidang pekerjaannya dalam hal ini tentu untuk meningkatkan efektifitas dan efesiensi kerja tidak terkecuali dalam kinerja akademik dalam pengelolaan monitoring.

Monitoring adalah suatu upaya pengumpulan informasi tentang pelaksanaan program dalam rangka membantu pengelola program untuk menjawab segala pernyataan berkaitan dengan kegiatan yang dilakukan. Hasil dari monitoring ini digunakan sebagai bahan dalam penyusunan laporan pelaksanaan program, disamping juga sebagai masukan dalam mengevaluasi program (Depdiknas, 2009).

Monitoring perkuliahan adalah suatu kegiatan pemantuan yang dilakukan pada suatu perguruan tinggi terhadap perkuliahan agar pelaksanaannya sesuai dengan rencana yang telah ditetapkan dan juga merupakan kegiatan pengawasan untuk peningkatan mutu proses belajar mengajar (PBM) beserta komponen pendukung PBM tersebut. Proses monitoring dilakukan terhadap operasional perkuliahan sehari-hari mulai dari proses awal kuliah hingga berakhirnya satu semester perkuliahan.

Berdasarkan permasalahan di atas maka penelitian ini dilakukan dengan tujuan untuk menjamin kualitas sistem monitoring perkuliahan agar tidak terjadi error serta fitur dan fungsionalitasnya menggunakan standar ISO 25010. Pengujian menggunakan karakteristik functional suitability, usability, reliability, performance efficiency, dan maintainability.

\section{METODE PENELITIAN}

A. Tempat dan Waktu Penelitian

Penelitian pengujian sistem monitoring perkuliahan dilakasanakan pada Program Studi Pendidikan Teknik Informatika dan Komputer Universitas Negeri Makassar dilaksanakan pada bulan September 2019 - Februari 2020. 


\section{B. Subjek Penelitian}

Subjek penelitian pada karakteristik functional suitability yaitu 2 responden ahli pengembang perangkat lunak. Subjek penelitian pada karakteristik usability menggunakan 30 responden yang terdiri dari 20 Dosen dan 10 Masiswa di Program Studi Pendidikan Teknik Informatika dan Komputer Fakultas teknik Universita Negeri Makassar.

\section{Pengujian Sistem}

Untuk pengembangan sistem monitoring perkuliahan secara realtime, metode pengujian yang digunakan dalam penelitian ini adalah uji kelayakan standar ISO 25010.

Pengujian functional suitability menggunakan metode blackbox testing yang dilakukan oleh ahli dalam bidang web development. Pengujian dilakukan dengan mengisi kuesioner yang disusun sesuai dengan analisis kebutuhan fungsionalitas. Instrumen subkarakteristik functional suitability memiliki 28 . Pengujian usability menggunakan USE Questionnaire oleh Arnold M. Lund (2001) dengan jumlah 20 pertanyaan. Terdapat empat kriteria dalam USE Questionnaire yaitu usefullness, ease of use, ease of learning, dan satisfaction. Pengujian reliability dilakukan dengan stress testing menggunakan software Server Stress Tools yang dapat memberikan sejumlah beban kepada perangkat lunak sehingga dapat diketahui apakah perangkat lunak berjalan baik saat diberi beban. Pengujian performance efficiency dilakukan dengan load testing menggunakan software GTMetrix. GTMetrix akan menghasilkan performance scores yang meliputi page speed score dan Yslow score serta page details yang meliputi fully load time, total page size, dan request. Pengujian pada aspek maintainability menggunakan ukuran yang diuji oleh peneliti langsung di lapangan secara operasional, sesuai dengan instrument pengujian yang disebutkan oleh Land, pengujian ini meliputi 3 aspek yaitu instrumentation, consistency dan simplicity.

\section{Teknik Analisis Data}

1. Aspek Functionality Suitability

Pada aspek functional suitability, menggunakan instrumen penelitian berupa testcase dengan skala Guttman. Skala guttman digunakan untuk mendapatakan jawaban yang tegas terhadap suatu permasalahan yang ingin dinyatakan. Skala pengukuran dengan tipe ini didapat jawaban yang tegas, yaitu "Ya" atau "Tidak", Ya bernilai 1 dan Tidak bernilai 0 pada tiap item. Testcase diberikan kepada 2 ahli media/sistem. Sementara hasil dari pengujian yang dilakukan oleh validator ahli dapat diukur dengan.

Tabel 1. Kategori Pemberian Skor Alternatif Jawaban

\begin{tabular}{|c|c|c|}
\hline \multirow{2}{*}{ Jawaban } & \multicolumn{2}{|c|}{ Skor Oleh Validator } \\
\cline { 2 - 3 } & Validator 1 & Validator 2 \\
\hline Ya & - & - \\
\hline Tidak & - & - \\
\hline Total & - & - \\
\hline
\end{tabular}

Sumber: Sugiyono. 2014

Persentase untuk masing-masing penilaian adalah:

$\mathrm{Ya}=\left(\sum\right.$ skor/item pertanyaan $) \times 100 \%$

Data yang terkumpul dianalisis dengan teknik analisis deskriptif kualitatif yang diungkapkan dalam distribusi frekuensi dan persentase terhadap kategori skala penilaian yang telah ditentukan dari penyajian dalam bentuk persentase. Selanjutnya, apabila persentase kelayakan sudah didapat maka dapat ditarik kesimpulan menjadi data kualitatif dengan menggunakan tabel konversi seperti berikut.
Tabel 2. Konversi Kualitatif dari presentase kelayakan

\begin{tabular}{|l|l|}
\hline \multicolumn{1}{|c|}{ Presentase Kelayakan } & \multicolumn{1}{c|}{ Kriteria } \\
\hline$\geq 50 \%$ & Dapat diterima \\
\hline$<50 \%$ & Ditolak \\
\hline Sugiyono, 2014
\end{tabular}

\section{a. Aspek Usability}

Analisis kualitas untuk karakteristik usability dilakukan dengan menganalisis respon pengguna dengan menggunakan skala dengan 5 pilihan (Rahadi: 2014). Skala dengan 5 pilihan tersebut merupakan skala likert. Skala likert merupakan jenis skala yang digunakan untuk mengukur sikap, pendapat, dan persepsi seseorang atau sekelompok orang tentang fenomena sosial (Sugiyono: 2014). Subjek penelitian pada responden menggunakan 30 responden yang merupakan Dosen dan Mahasiswa Program Studi Pendidikan Teknik Informatika dan Komputer Fakultas Teknik Universitas Negeri Makassar. Menurut Nielsen (2012), jumlah responden untuk menguji usubility minimal menggunakan 20 orang.

Skor untuk alternatif jawaban untuk setiap item sebagai berikut: (1) Skor 5 untuk jawaban sangat setuju, (2) Skor 4 untuk jawaban setuju, (3) Skor 3 untuk jawaban kurang setuju, (4) skor 2 untuk jawaban tidak setuju dan (5) Skor 1 untuk jawaban sangat tidak setuju.

Pengujian karakteristik usability menggunakan teknik analisis deskriptif dimana analisis diperlukan agar dapat menjelaskan suatu data dengan mendeskripsikanya, sehingga diperoleh kesimpulan dari sekelompok data tersebut. Skor tersebut dihitung menggunakan rumus konversi ke presentase skor untuk mencari kriteria interprestasi skor hasil pengujian usability. Berikut ini adalah rumus konversi ke persentase skor.

$$
\text { Persentase Usability }=\frac{\text { Skor Perolehan }}{\text { Skor Maksimal }} \times 100 \%
$$

Hasil dari persentase skor tersebut kemudian dibandingkan dengan tabel kriteria interpretasi skor. Kriteria interprestasi skor dapat dilihat pada Tabel 3.

Tabel 3. Kriteria Interpretasi Skor

\begin{tabular}{|c|c|}
\hline Persentase Skor & Keterangan \\
\hline $0 \%-20 \%$ & Sangat Tidak Baik \\
\hline $20 \%-40 \%$ & Tidak Baik \\
\hline $40 \%-60 \%$ & Netral \\
\hline $60 \%-80 \%$ & Baik \\
\hline $80 \%-100 \%$ & Sangat Baik \\
\hline
\end{tabular}

\section{b. Aspek Reliability}

Pengujian realibility dimaksudkan untuk menguji kehandalan atau keterpercayaan sistem. Pengujian realibilty dilakukan dengan aplikasi webserver stress tool dengan melakukan pengujian kinerja sistem ketika sedang bekerja. Hasil Laporan stress testing harus memenuhi standar tingkas kesalahan kurang dari 1\% (Lisitsyn, 2011). Sehingga pengujian karakteristik realibility dikatakan tinggi. Jika sistem mampu menghasilkan tingkat keberhasilan lebih dari $90 \%$ dalam kondisi beban load yang diperkirakan.

\section{c. Aspek performance efficiency}

Pengujian performance efficiency dimaksudkan untuk menguji tingkat efisiensi performa dari aplikasi yang dikembangkan. Pengujian performance efficiency dilakukan dengan aplikasi software GTMetrix, dengan melakukan pengujian 
efisiensi performa sistem ketika sedang bekerja. Hasil Laporan GTMetrix harus memenuhi waktu load kurang dari 10 detik. Sehingga pengujian karakteristik realibility dikatakan tinggi.

\section{d. Pengujian Maintability}

Pengujian pada aspek maintainability menggunakan ukuran yang diuji oleh peneliti langsung di lapangan secara operasional, sesuai dengan instrument pengujian yang disebutkan oleh Land, pengujian ini meliputi 3 aspek yaitu instrumentation, consistency dan simplicity.

\begin{tabular}{|l|l|}
\multicolumn{1}{|c|}{ Tabel 4. Analisis Hasil Pengujian Maintainability } \\
\begin{tabular}{|l|l|}
\hline \multicolumn{1}{|c|}{ Pspek } & \multicolumn{1}{c|}{ Penilaian } \\
\hline Instrumentation & $\begin{array}{l}\text { Terdapat peringatan dari sistem jika terjadi } \\
\text { kesalahan beserta identifikasi kesalahan }\end{array}$ \\
\hline Consistency & $\begin{array}{l}\text { Penggunaan satu model rancangan pada } \\
\text { seluruh rancangan sistem }\end{array}$ \\
\hline Simplicity & $\begin{array}{l}\text { Kemudahan dalam pengelolaan, perbaikan, dan } \\
\text { pengembangan sistem }\end{array}$ \\
\hline
\end{tabular}
\end{tabular}

\section{HASIL PENELITIAN}

Berikut ini hasil pengujian sistem monitoring perkuliahan yang telah dikembangkan berdasarkan standar kualitas perangkat lunak ISO 25010 yang terdiri dari aspek functional suitability, aspek usability, aspek reliability, dan aspek performance Efeciency, dan maintability.

a. Pengujian Functional Suitability

Uji validasi ahli sistem berfungsi untuk mengetahui kelayakan dari sistem monitoring perkuliahan yang telah dikembangkan. Hasil dari uji validasi ahli sistem kemudian dijadikan bahan perbaikan media sistem yang dikembangkan. Setiap fungsi dinilai oleh 2 (dua) orang ahli sistem.

Hasil pengujian dan penilaian aspek functionality suitability oleh ahli sistem terhadap produk yang dikembangkan ditunjukkan dalam Tabel 5.

Tabel 5. Hasil Pengujian Uji Functional Suitability

\begin{tabular}{|c|c|c|c|c|}
\hline \multirow{2}{*}{$\begin{array}{l}\mathrm{N} \\
\mathrm{O} .\end{array}$} & \multirow{2}{*}{$\begin{array}{l}\text { FITUR } \\
\text { YANG } \\
\text { DIUJI }\end{array}$} & \multirow{2}{*}{$\begin{array}{l}\text { HASIL YANG } \\
\text { DIHARAPKAN }\end{array}$} & \multicolumn{2}{|c|}{ JAWABAN } \\
\hline & & & $\begin{array}{c}\text { Val. } \\
1\end{array}$ & $\begin{array}{c}\text { Val. } \\
2\end{array}$ \\
\hline \multicolumn{5}{|c|}{ Halaman Login } \\
\hline 1. & $\begin{array}{l}\text { Menu login } \\
\text { admin }\end{array}$ & $\begin{array}{l}\text { Menu login admin } \\
\text { menampilkan form } \\
\text { login yang berisi input } \\
\text { username, input } \\
\text { pasword, dan tombol } \\
\text { login }\end{array}$ & 1 & 1 \\
\hline 2. & $\begin{array}{l}\text { Notifikasi } \\
\text { kesalahan } \\
\text { login }\end{array}$ & $\begin{array}{l}\text { Menampilkan } \\
\text { notifikasi kesalahan } \\
\text { peninputan username } \\
\text { dan pasword }\end{array}$ & 1 & 1 \\
\hline 3. & $\begin{array}{l}\text { Tombol } \\
\text { Login }\end{array}$ & $\begin{array}{l}\text { Berfungsi dengan } \\
\text { baik jika username } \\
\text { dan pasword } \text { benar }\end{array}$ & 1 & 1 \\
\hline \multicolumn{5}{|c|}{ Halaman Admin } \\
\hline 4. & $\begin{array}{c}\text { Menu } \\
\text { dashboard }\end{array}$ & $\begin{array}{l}\text { Menu dashboard } \\
\text { berfungsi dengan baik }\end{array}$ & 1 & 1 \\
\hline 5. & $\begin{array}{c}\text { Menu } \\
\text { master tabel }\end{array}$ & $\begin{array}{l}\text { Menu pengguna untuk } \\
\text { menambahkan user }\end{array}$ & 1 & 1 \\
\hline
\end{tabular}

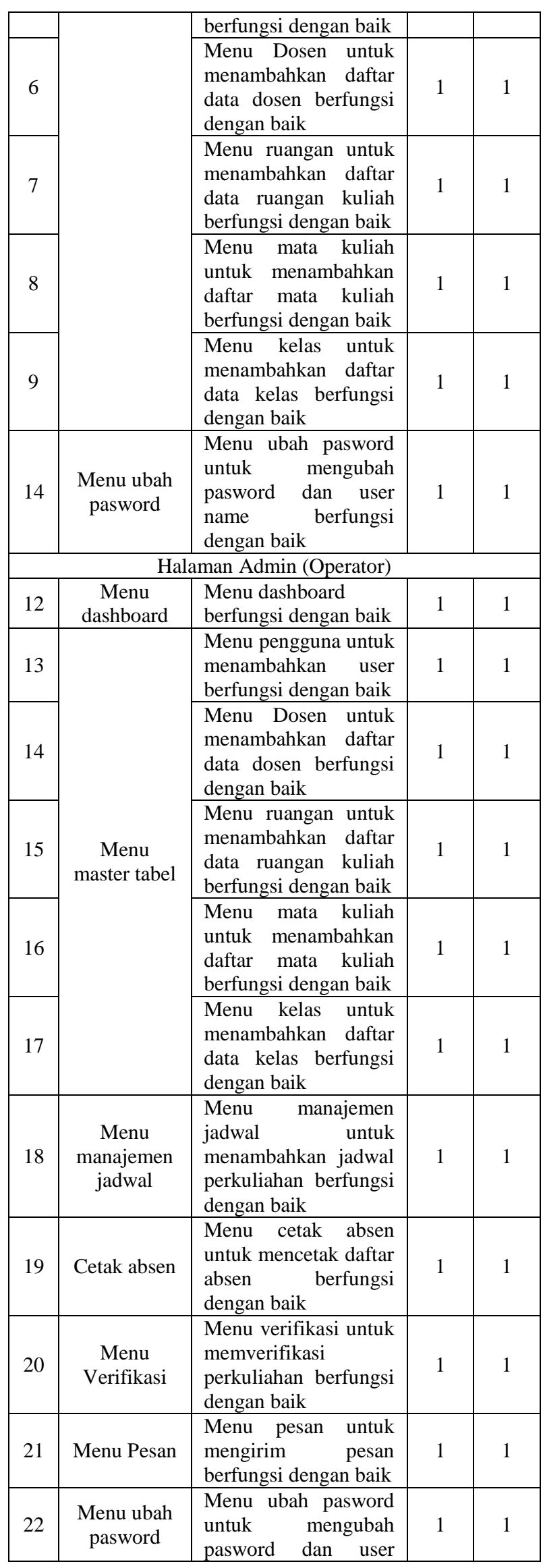




\begin{tabular}{|c|c|c|c|c|}
\hline & & $\begin{array}{l}\text { name berfungsi } \\
\text { dengan baik }\end{array}$ & & \\
\hline \multicolumn{5}{|c|}{ Halaman Dosen } \\
\hline 23 & $\begin{array}{c}\text { Menu } \\
\text { dashboard }\end{array}$ & \begin{tabular}{lr} 
Menu & dashboard \\
memuat & jadwal \\
perkuliahan & yang \\
sedang berlangsung \\
dan & verifikasi \\
kehadiran & berfungsi \\
\multicolumn{2}{l}{ dengan baik }
\end{tabular} & 1 & 1 \\
\hline 24 & $\begin{array}{l}\text { Menu cari } \\
\text { jadwal }\end{array}$ & $\begin{array}{l}\text { Menu cari jadwal } \\
\text { untuk mencari jadwal } \\
\text { perkuliahan berfungsi } \\
\text { dengan baik }\end{array}$ & 1 & 1 \\
\hline 25 & $\begin{array}{l}\text { Menu ubah } \\
\text { pasword }\end{array}$ & $\begin{array}{l}\text { Menu ubah pasword } \\
\text { untuk mengubah } \\
\text { pasword dan user } \\
\text { name berfungsi } \\
\text { dengan baik }\end{array}$ & 1 & 1 \\
\hline \multicolumn{5}{|c|}{ Halaman Mahasiswa } \\
\hline 26 & $\begin{array}{c}\text { Menu } \\
\text { dashboard }\end{array}$ & \begin{tabular}{lr} 
Menu & dashboard \\
memuat & jadwal \\
perkuliahan & yang \\
sedang & berlangsung \\
dan & verifikasi \\
kehadiran & berfungsi \\
\multicolumn{2}{l}{ dengan baik }
\end{tabular} & 1 & 1 \\
\hline 27 & $\begin{array}{l}\text { Menu Cari } \\
\text { jadwal }\end{array}$ & $\begin{array}{l}\text { Menu cari jadwal } \\
\text { untuk mencari jadwal } \\
\text { perkuliahan berfungsi } \\
\text { dengan baik }\end{array}$ & 1 & 1 \\
\hline 28 & $\begin{array}{l}\text { Menu ubah } \\
\text { pasword }\end{array}$ & $\begin{array}{l}\text { Menu ubah pasword } \\
\text { untuk mengubah } \\
\text { pasword dan user } \\
\text { name berfungsi } \\
\text { dengan baik }\end{array}$ & 1 & 1 \\
\hline
\end{tabular}

Tabel 6. Rekapitulasi Hasil Penilaian Ahli Media/Sistem

\begin{tabular}{|c|c|c|}
\hline \multirow{2}{*}{ Jawaban } & \multicolumn{2}{|c|}{ Skor Oleh Validator } \\
\cline { 2 - 3 } & Validator 1 & Validator 2 \\
\hline Ya & 28 & 28 \\
\hline Tidak & - & - \\
\hline
\end{tabular}

Berdasarkan hasil pada tabel 5. dapat diketahui rata-rata persentase untuk masing-masing penilaian adalah:

(Total skor/item pertanyaan) $* 100 \%$

$=(28 / 28) \times 100 \%$

$=100 \%$

Berdasarkan perhitungan pada Tabel 6, maka diperoleh presentase $>50 \%$ dari pengujian functionality. Nilai tersebut kemudian dikonversi ke data kualitatif dan berdasarkan skala penilaian, dari skor persentase yang didapat maka kualitas perangkat lunak dari sisi functionality suitability dapat diterima dan telah sesuai dengan aspek functionality suitability. b. Pengujian Usuability

Uji usability dilakukan dengan menguji cobakan secara langsung kepada pengguna dengan jumlah responden sebanyak 30 responden dan 20 pertanyaan. Analisis hasil penilaian tanggapan responden usability dapat dilihat pada Tabel berikut.

Tabel 7. Rekapitulasi Hasil Pengujian Respon Pengguna Usability

\begin{tabular}{|c|c|c|c|}
\hline No Responden & Skor & $\begin{array}{c}\text { Skor } \\
\text { Maksimal }\end{array}$ & Persentase $(\%)$ \\
\hline 1 & 94 & 100 & 94 \\
\hline 2 & 100 & 100 & 100 \\
\hline 3 & 100 & 100 & 100 \\
\hline 4 & 84 & 100 & 84 \\
\hline 5 & 81 & 100 & 81 \\
\hline 6 & 98 & 100 & 98 \\
\hline 7 & 87 & 100 & 87 \\
\hline 8 & 98 & 100 & 98 \\
\hline 9 & 91 & 100 & 91 \\
\hline 10 & 84 & 100 & 84 \\
\hline 11 & 88 & 100 & 88 \\
\hline 12 & 84 & 100 & 84 \\
\hline 13 & 82 & 100 & 82 \\
\hline 14 & 90 & 100 & 90 \\
\hline 15 & 87 & 100 & 87 \\
\hline 16 & 91 & 100 & 91 \\
\hline 17 & 85 & 100 & 85 \\
\hline 18 & 87 & 100 & 87 \\
\hline 19 & 83 & 100 & 83 \\
\hline 20 & 90 & 100 & 90 \\
\hline 21 & 85 & 100 & 85 \\
\hline 22 & 91 & 100 & 91 \\
\hline 23 & 87 & 100 & 87 \\
\hline 24 & 87 & 100 & 87 \\
\hline 25 & 85 & 100 & 85 \\
\hline 26 & 91 & 100 & 91 \\
\hline 27 & 85 & 100 & 85 \\
\hline 28 & 83 & 100 & 83 \\
\hline 29 & 87 & 100 & 87 \\
\hline 30 & 90 & 100 & 90 \\
\hline Rata-rata & 2655 & 3000 & 88.5 \\
\hline
\end{tabular}

Persentase Usability $=\frac{\text { Skor } \text { yang diperoleh }}{\text { Skor Maksimal }} \times 100 \%$

Persentase usability $=2655 / 3000 \times 100 \%$

Psersentase usability $=88.5 \%$

Berdasarkan analisis perhitungan akhir diperoleh persentase $88.5 \%$ dalam pengujian usability. Skor tersebut menunjukkan bahwa kualitas perangkat lunak dari aspek usability telah sesuai dan jika diinterpretasikan dengan skala Likert termasuk dalam kategori sangat baik.

\section{c. Pengujian Reability}

Pengujian reability sistem menggunakan aplikasi Web Server Stress Teools untuk melihat simulasi pengunjung sistem yang 
besar. Jika sistem dapat berhasil melewati pengujian ini tanpa gangguan berarti aplikasi dapat dinyatakan reliabel. Pada pengujian menggunakan aplikasi ini terdapat tiga pengujian yaitu click test, time test, dan ramp test.

\section{Click Test}

Click test adalah pengujian (runt test) dengan jumlah load constant (beban konstan) hingga user memenuhi jumlah klik yang telah digenerasi. Berikut adalah hasil pengujian click test dengan jumlah virtual user sebanyak 10 orang, tidak terdapat waktu delay, dan jumlah klik sebanyak 5 kali. Hasil pengujian click test dapat dilihat pada gambar 1.

\begin{tabular}{|r|r|r|r|r|r|r|r|}
\hline \multicolumn{1}{|l|}{ Logfiles } & \multicolumn{3}{|c|}{ Results per User (Complete Test) } & \multicolumn{3}{|c|}{ Results per URL (Complete Test) } \\
\hline User No. & Clicks & Hits & Errors & Avg. Click Time [ms] & Bytes & kbit/s & Cookies \\
\hline 1 & 1 & 1 & 0 & 483 & 4.919 & 81,46 & \\
\hline 2 & 1 & 1 & 0 & 410 & 4.919 & 96,04 & \\
\hline 3 & 1 & 1 & 0 & 136 & 1.036 & 61,09 & \\
\hline 4 & 1 & 1 & 0 & 507 & 4.919 & 77,61 & \\
\hline 5 & 1 & 1 & 0 & 495 & 4.919 & 79,49 & \\
\hline 6 & 1 & 1 & 0 & 491 & 4.919 & 80,21 & \\
\hline 7 & 1 & 1 & 0 & 494 & 4.919 & 79,71 & \\
\hline 8 & 1 & 1 & 0 & 461 & 4.919 & 85,31 & \\
\hline 9 & 1 & 1 & 0 & 443 & 4.919 & 88,77 & \\
\hline 10 & 1 & 1 & 0 & 470 & 4.919 & 83,67 & \\
\hline & & & & & &
\end{tabular}

Gambar 1. Hasil Click Test per User

Berdasarkan Gambar 1 dengan jumlah user sebanyak 10 dan jumlah klik sebanyak 5 kali menghasilkan tingkat error nol atau tidak ditemukan kesalahan, Avg. click time dengan nilai antara 136-507 ms, dan waktu untuk pengiriman dari server antara 1.036-.919 byte serta waktu yang diperlukan untuk mengakses halaman sebesar 61.09-96.04 kbit/s

\section{Time Test}

Time test adalah pengujian dengan jumlah beban konstan (load constant) pada waktu yang telah ditentukan. Pengujian time test dilakukan dalam waktu 60 menit dengan jumlah virtual user 5 orang dan waktu delay peruser 20 . Hasil pengujian time test dapat dilihat pada Gambar 2 .

\begin{tabular}{|c|c|c|c|c|c|c|c|c|}
\hline Logfiles & \multicolumn{4}{|c|}{ Results per User (Complete Test) } & \multicolumn{4}{|c|}{ Results per URL (Complete Test) } \\
\hline User No. & Clicks & Hits & Errors & Avg. Click Time [ & ms] & Bytes & $\mathrm{kbit} / \mathrm{s}$ & Cookies \\
\hline 1 & 139 & 139 & 0 & 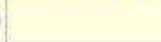 & 792 & 497.484 & 36,14 & \\
\hline 2 & 138 & 138 & 0 & & 850 & 636.092 & 43,38 & \\
\hline 3 & 137 & 137 & 0 & & 960 & 731.613 & 44,52 & \\
\hline 4 & 137 & 137 & 0 & & 914 & 646.740 & 41,32 & \\
\hline 5 & 137 & 137 & 0 & & 887 & 666.120 & 43,84 & \\
\hline
\end{tabular}

Gambar 2. Hasil Time Test per User

Hasil Pengujian Time Test Peruser Berdasarkan Gambar 2 dengan jumlah user sebanyak 5 orang diperolah click sebanyak 137-138 kali, pada pengujian time test ini tidak ditemukan kesalahana atau tingkat error nol. Avg. click time antara 792-960 ms dan waktu untuk pengiriman dari server sebesar 497.484731.613 byte serta waktu yang diperlukan untuk mengkases halaman sebesar 36.14-44.52 kbit/s.

\section{Ramp Test}

Ramp test adalah pengujian dengan jumlah beban (load) yang semakin meningkat pada waktu yang telah ditentukan.

\begin{tabular}{|c|c|c|c|c|c|c|c|c|}
\hline \multirow{2}{*}{$\begin{array}{l}\text { Logfiles } \\
\text { User No. }\end{array}$} & \multicolumn{4}{|c|}{ Results per User (Complete Test) } & \multicolumn{4}{|c|}{ Results per URL (Complete Test } \\
\hline & Clicks & Hits & Errors & Avg. Click Time [n & [ms] & Bytes & kbit/s & Cookies \\
\hline 1 & 97 & 7. 97 & 0 & & 188 & 206.598 & 90,79 & \\
\hline 2 & 68 & 68 & 0 & & 271 & 206.598 & 89,58 & \\
\hline 3 & 44 & 43 & 0 & & 655 & 206.598 & 58,69 & \\
\hline 4 & 44 & 43 & 0 & & 541 & 191.086 & 65,72 & \\
\hline 5 & 44 & $4 \quad 43$ & 0 & & 484 & 140.587 & 54,07 & \\
\hline
\end{tabular}

Gambar 3. Hasil Ramp Test per User

Pengujian ramp test dilakukan dengan waktu 10 menit, dengan jumlah virtual user sebanyak 10 orang, dan tidak terdapat waktu delay antar user. Hasil pengujian ramp test dapat dilihat pada Gambar 3

Berdasarkan Gambar 3 dengan jumlah user 10 orang diperoleh click sebanyak 44-97 kali, pada pengujian ramp test ini tidak ditemukan kesalahan atau tingkat error nol. Avg. click time antara 188-655 ms dan waktu untuk pengiriman dari server sebesar 140.587-206.598 byte serta waktu yang diperlukan untuk mengakses halaman sebesar 54.07-90.79 kbit/s.

Berdasarkan hasil pengujian ketiga jenis test dengan menggunakan click test, time test, dan ramp test maka dapat disimpulkan bahwa persentase kesuksesan dari pengujian sebesar $100 \%$, adapaun uraiannya dapat dilihat pada tabel 8 .

Tabel 8. Hasil Pengujian Reability

\begin{tabular}{|c|c|c|}
\hline Jenis Tes & $\begin{array}{c}\text { Persentase Error } \\
\text { Per Test }\end{array}$ & $\begin{array}{c}\text { Persentase Sukses Per } \\
\text { test }\end{array}$ \\
\hline Click Test & $0 \%$ & $100 \%$ \\
\hline Time Test & $0 \%$ & $100 \%$ \\
\hline Ramp Test & $0 \%$ & $100 \%$ \\
\hline & Rata-rata & $100 \%$ \\
\hline
\end{tabular}

Berdasarkan tabel 8 di atas, diperoleh rata-rata presentase sukses per test sebesar $100 \%$ hal ini berarti bahwa sistem yang dikembangkan memiliki reabilty tinggi.

\section{d. Pengujian performance efficiency.}

Pengujian ini dilakukan dengan menghitung nilai skor dari halaman dan waktu respon yang diujikan menggunakan GTMetrix. Halaman dan waktu respon yang diujikan menggunakan GTMetrix. Hasil page speed sebesar $55 \%$ YsLow sebesar $68 \%$ dan waktu load sebesar 4.2 detik. Web dikatakan baik apabila waktu load setidaknya kurang dari 10 detik. Dari hasil tersebut sehingga dapat disimpulkan bahwa sistem monitoring perkuliahan yang dikembangkan telah memenuhi karakteristik performance efficiency.

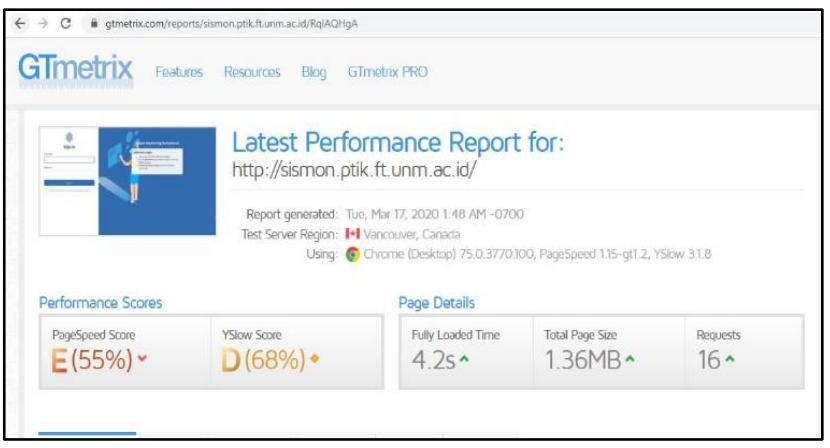

Gambar 4. Hasil analisis performance effieciency menggunakan GTMetrix 


\section{e. Pengujian maintainability}

Pengujian pada aspek maintainability menggunakan ukuran yang diuji oleh peneliti langsung di lapangan secara operasional, sesuai dengan instrument pengujian yang disebutkan oleh Land, pengujian ini meliputi 3 aspek yaitu instrumentation, consistency dan simplicity. Hasil dari pengujian maintainability dapat dilihat pada gambar di bawah apabila terjadi kesalahan input atau masukan yang digunakan oleh pengguna, maka sistem akan secara otomatis memberikan pesan peringatan.

\section{1) Login}

Adanya pemberitahuan jika login tidak sesuai dengan user dan password

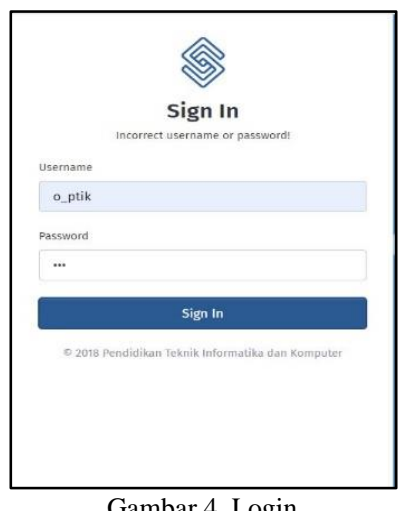

2) Mengubah foto profil

Pada gambar di bawah ini menunjukkan bahwa adanya peringatan kepada user jika format yang dimasukkan salah.

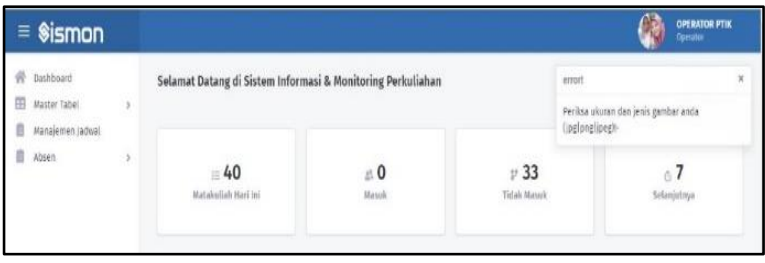

Gambar 5. Mengubah Foto Profil

3) Keterangan Berhasil Input jadwal

Pada gambar di bawah ini menunjukkan bahwa adanya info kepada user jika data yang dimasukkan berhasil

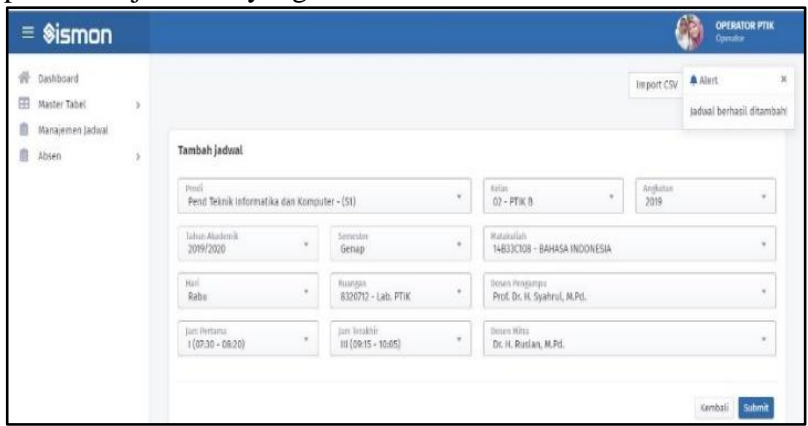

Gambar 6. Peringatan kesalahan upload foto profil

4) Keterangan Berhasil verifikasi kehadiran

Adanya tanda tulisan berwarna hijau jika mata kuliah tersebut telah dilaksanakan

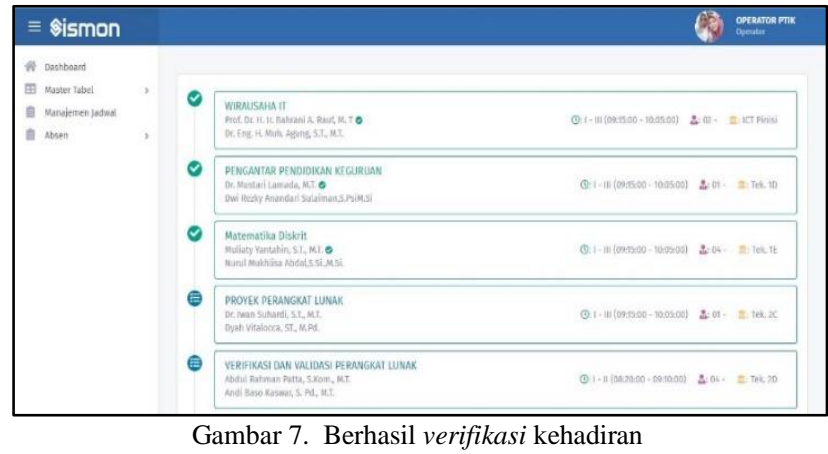

Analisis untuk pengujian maintainability sesuai dengan instrument pengujian Land terdapat dalam tabel di bawah ini:

\begin{tabular}{|c|c|c|}
\hline Aspek & Penilaian & Hasil \\
\hline Instrumentation & $\begin{array}{l}\text { Terdapat } \\
\text { peringatan dari } \\
\text { sistem jika terjadi } \\
\text { kesalahan beserta } \\
\text { identifikasi } \\
\text { kesalahan }\end{array}$ & $\begin{array}{l}\text { Ketika ada kesalahan } \\
\text { yang dilakukan oleh } \\
\text { user, sistem } \\
\text { mengeluarkan } \\
\text { peringatan untuk } \\
\text { mengidentifikasi } \\
\text { kesalahan. Contoh, } \\
\text { ketika user } \\
\text { memasukkan pasword } \\
\text { dan username yang } \\
\text { salah maka akan } \\
\text { muncul peringatan agar } \\
\text { melengkapai data, jika } \\
\text { user berhasil } \\
\text { menginput data akan } \\
\text { muncul informasi } \\
\text { keterangan data } \\
\text { berhasil diinput, jika } \\
\text { user mengupload foto } \\
\text { profil dengan format } \\
\text { yang salah maka akan } \\
\text { muncul peringatan, jika } \\
\text { verifikasi kehadiran } \\
\text { berhasil maka tulisan } \\
\text { mata kuliah tersebut } \\
\text { berubah warna hijau. }\end{array}$ \\
\hline Consistency & $\begin{array}{l}\text { Penggunaan satu } \\
\text { model rancangan } \\
\text { pada seluruh } \\
\text { rancangan sistem }\end{array}$ & $\begin{array}{l}\text { Model rancangan } \\
\text { sistem } \\
\text { mempunyai telah } \\
\text { bentuk yang sama. Hal } \\
\text { ini dapat dilihat pada } \\
\text { bagian implementasi } \\
\text { sistem, yaitu tampilan } \\
\text { halaman web dari satu } \\
\text { halaman ke halaman } \\
\text { lainnya memiliki } \\
\text { kemiripan, bentuk yang } \\
\text { serupa, dan konsisten. }\end{array}$ \\
\hline Simplicity & $\begin{array}{l}\text { Kemudahan } \\
\text { dalam } \\
\text { pengelolaan, } \\
\text { perbaikan, dan } \\
\text { pengembangan } \\
\text { sistem }\end{array}$ & $\begin{array}{lr}\text { Hasil pengujian } \\
\text { menunjukan bahwa } \\
\text { sistem mudah untuk } \\
\text { diperbaiki dan } \\
\text { dikembangkan, karena } \\
\text { dibuat menggunakan }\end{array}$ \\
\hline
\end{tabular}




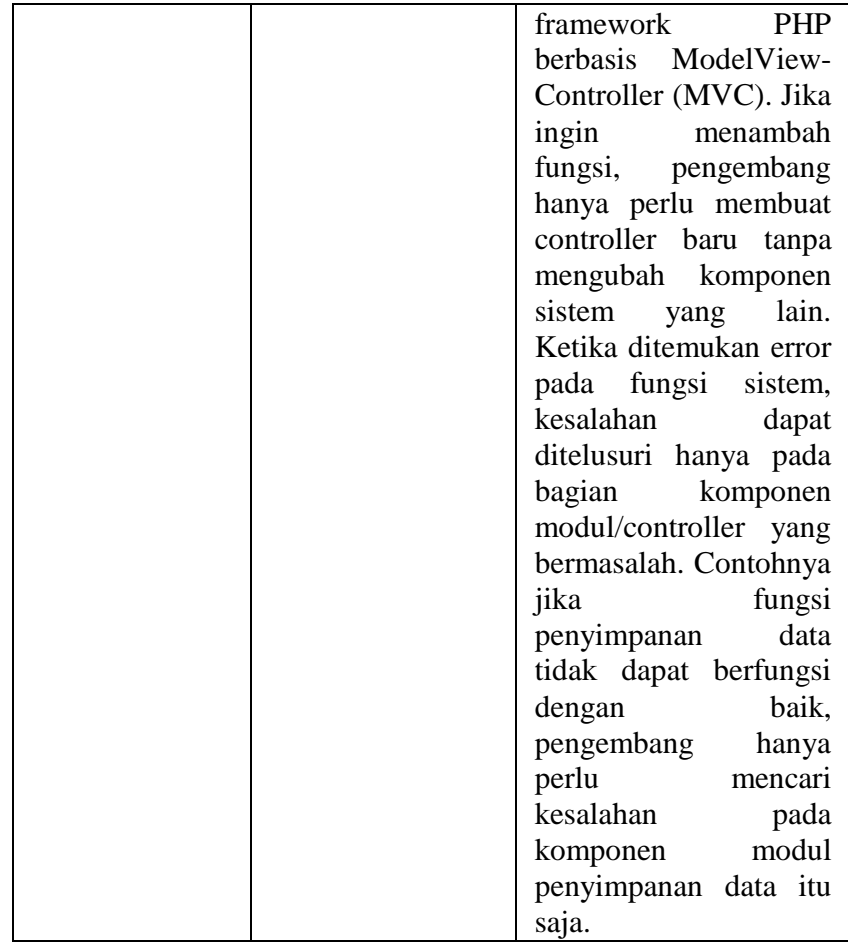

\section{KESIMPULAN}

Berdasarkan hasil penelitian yang telah dilakukan dapat disimpulkan bahwa:

1. Pengujian Aplikasi Sistem Monitoring Perkuliahan Menggunakan Standar ISO 25010 yang terdiri dari aspek functional suitability, aspek usability, aspek reliability, dan aspek performance Efeciency, dan maintability.

2. Hasil pengujian perangkat lunak berdasarkan standar kualitas ISO 25010 diperoleh hasil:

a. Aspek functional suitability dari Pengujian Aplikasi Sistem Monitoring Perkuliahan Menggunakan Standar ISO 25010berada pada kategori baik dengan nilai $100 \%$.

b. Aspek pengujian Usuability dari Pengujian Aplikasi Sistem Monitoring Perkuliahan Menggunakan Standar ISO 25010 berada pada kategori sangat layak dengan presentase hasil penelitian yang didapatkan yaitu rata-rata $88.5 \%$.

c. Aspek realibility dari Pengujian Aplikasi Sistem Monitoring Perkuliahan Menggunakan Standar ISO 25010 telah memenuhi aspek realibility dengan rata-rata persentase sukses per user sebesar $100 \%$ dan rata-rata persentase sukses per URL sebesar $100 \%$.

d. Aspek pengujian performance efficiency realibility dari Pengujian Aplikasi Sistem Monitoring Perkuliahan Menggunakan Standar ISO 25010 pada kategori dapat diterima dengan waktu load sebesar 4,2 detik.

e. Aspek maintainability dari Pengujian Aplikasi Sistem Monitoring Perkuliahan Menggunakan Standar ISO 25010 sebesar 100 dengan kategori sangat mudah dirawat.

\section{DAFTAR PUSTAKA}

[1] Sudarmawan, Dony Ariyus. 2007. Interaksi Manusia dan Komputer. Yogyakarta: ANDI

[2] Maniah, Dini Hamidin. 2017. Analisis dan Perancangan Sistem Informasi Pembahasan Secara Praktis dengan Contoh Kasus. Yogyakarta: Deepublish.

[3] Nusa Putra. 2011. Research and Development. Jakarta: PT. Raja Grafindo Persada. Halaman 133.
[4] Satzinger, dkk. 2010. "Sistem Analisis and Design with the Unifed process". USA: Course Technology Cengage Learning.

[5] McLeod, Raymon Jr dan George P. Schell. (2010). Sistem Informasi Manajemen. Jakarta: Indeks.

[6] Laudon, Kenneth C., \& Jane, P. Laudon. (2010). Manajemen Information Sistem:

[7] Managing the Digital Firm. New Jersey: Prentice-Hall.

[8] Whitten and Bentley. 2007. Sistem Analisys And Design For the Global Enterprise Seventh Edition, NewYork.

[9] Al-bahra bin Ladjamudin. 2005. Analisis dan Desain Sistem Informasi. Graha Ilmu. Yogyakarta.

[10] George M. Scott, Prinsip-Prinsip Sistem Informasi Manajemen, RajaGrafindo Persada, Jakarta, 2001

[11] Sutarman. 2012. Buku Pengantar Teknologi Informasi. Jakarta: Bumi Aksara.

[12] Nugroho, Adi. 2013. E-commerce. Informatika Bandung. Bandung.

[13] Kadir,Abdul. 2009. "Membuat Aplikasi Web dengan PHP dan Database MySQL". Yogyakarta: Andi Offset.

[14] Puspitasari. 2011. Pemrograman Web Database dengan PHP \& MySQL. Jakarta: Skripta.

[15] Sommerville, Ian. 2011. Software Engineering (Rekayasa Perangkat Lunak. Jakarta: Erlangga.

[16] Undang-Undang Republik Indonesia Nomor 43 Tahun 2009 Tentang Kearsipan Peraturan Guberbur 11 Tentang Pengelolaan Arsip Dinamis. 2009. Jakarta: Republik Indonesia. 